\title{
Numerical schemes based on the stress compensation method framework for creep rupture assessment
}

\author{
Heng Penga, Yinghua Liu ${ }^{\mathrm{a},}$, , Haofeng Chen ${ }^{\mathrm{b}, *}$ \\ a Department of Engineering Mechanics, AML, Tsinghua University, Beijing 100084, People's Republic of China \\ ${ }^{b}$ Department of Mechanical and Aerospace Engineering, University of Strathclyde, Glasgow G1 1XJ, UK
}

*Corresponding authors: yhliu@mail.tsinghua.edu.cn; haofeng.chen@strath.ac.uk

\begin{abstract}
Evaluation of creep rupture limit and prediction of creep rupture life are two significant issues for high-temperature devices under the action of cyclic thermo-mechanical loadings. In this paper, the shakedown solution procedure proposed recently by the authors, so-called stress compensation method (SCM), is extended for creep rupture assessment via an extended shakedown theory including creep. Two distinct numerical schemes based on the SCM framework are presented, where Scheme 1 is utilised for evaluation of creep rupture limit and Scheme 2 is utilised for prediction of creep rupture life. Instead of using the detailed creep constitutive equations, the present methods just need to know several material parameters including the creep rupture data. A holed plate is provided as a typical example to validate the reliability of two numerical schemes. Detailed cycle-by-cycle analyses are carried out to illustrate the good accuracy of these calculated creep rupture limits and reveal the failure mechanisms of the structure under different combinations of loads. A numerical study on a pipe junction is also conducted to show the engineering application of the methods. As a result, the two numerical schemes are proved to be effective and reliable for solving practical industrial problems.
\end{abstract}

Keywords: Creep rupture; Rupture time; Shakedown; Stress compensation method; Numerical scheme

\section{Introduction}

Many structural devices in nuclear power, energy, aviation, and petrochemical industries are made of ductile metallic materials and operate in high temperature environment. Most of the typical structural elements bear complex loading conditions including internal pressure and thermal loading, 
and the temperature and applied loads often change. The structural elements operating at the creep temperature range exhibit time-dependent deformation behavior while other elements operating below the creep temperature exhibit time-independent plasticity behavior. In such cases, it is not only ductile rupture by the excessive or cyclic plastic deformation but also creep rupture by the long-term accumulation of creep damage that should be concerned for structural safety design and life assessment. In general, the ductile rupture problem can be solved through the plastic limit and shakedown analysis where the maximum permissible load of a structure is calculated. For the creep rupture problem, both the maximum permissible load and the creep rupture life of the structure are concerned.

Creep rupture can be considered as the result of cumulative creep damage that generates from the void growth and coalescence in material microstructures. The creep rupture strength of a material is identified by the uniaxial testing, and is related to the environment temperature and load-holding time. A feasible approach to assess creep rupture is to simulate the material degenerative process of a component under the specific loading and temperature conditions using creep damage models. The typical creep damage models include the Kachanov-Rabotnov model (Kachanov, 1958; Rabotnov, 1969), Liu-Murakami model (Murakami, 2000), Dyson model (Dyson, 2000) and so on. However, it is known that more than six creep parameters are required to describe these models in constitutive equations, which are difficult to acquire and even not always available. Furthermore, it is often timeconsuming and cumbersome to simulate the entire process of creep damage for engineering structures in creep analysis, especially when cyclic loading conditions are considered. For industrial application, some simplified structural analysis methods, which are based upon the limit analysis and shakedown concepts and make full use of the creep rupture data, are utilised in integrity assessment procedure R5 (Ainsworth, 2003) and ASME NH (ASME, 2013). Such methods are able to directly simulate the creep rupture phenomenon without needing the development of detailed constitutive descriptions but a small number of material parameters, and can provide simple but reasonable assessment results (Barbera and Chen, 2015; Chen et al., 2003; Chen et al., 2006).

The linear matching method (LMM) (Chen and Ponter, 2001), matching the nonlinear material behavior to a linear one, was originally proposed for evaluation of plastic limit and shakedown limit loads of elastoplastic structures. For the sake of evaluating the maximum permissible load or predicting the creep rupture life of creeping structures, Chen et al. (2003) extended the LMM to include the creep rupture effect via combining the shakedown analysis procedure with creep rupture data (Barbera and 
Chen, 2015; Chen et al., 2006), achieving the same function but with more accurate results as these simplified methods in integrity assessment procedure R5 (Ainsworth, 2003). In this way, the assessment of creep rupture limit was essentially translated into a shakedown analysis with a revised yield strength. The revised yield strength parameter was determined by the smaller one of the yield strength and the creep rupture strength.

Recently, a novel direct method, so-called stress compensation method (SCM) was presented by the authors of this paper (Peng et al., 2019a, b; Peng et al., 2018) to evaluate the plastic limit and shakedown limit loads of elastoplastic structures under complex thermo-mechanical loadings. The SCM just executes a series of iterative computations of finite element (FE) equilibrium equations, where the structural stiffness matrix keeps constant and is assembled and decomposed only once, rather than generating the traditional mathematical programming formulation and further solving the optimisation problem. The SCM has computational advantages in solving large-scale shakedown problem for complex engineering structures under multiple loading systems. Nevertheless, the current SCM is merely applied for shakedown and limit analysis of elastoplastic structures at normal temperature and unavailable to evaluate the loading-carry capacity of structures with consideration of high temperature creep rupture.

The aim of this paper is to extend the SCM for creep rupture assessment, including the evaluation of maximum permissible load of a component within the prescribed creep rupture life and the prediction of creep rupture life of a component under the prescribed loading condition. Two distinct numerical schemes based on the SCM framework are proposed to solve the corresponding creep rupture problems. The outline of this paper is as follows: Following a statement of the extended shakedown theory including creep in Section 2, two numerical schemes based on the SCM proposed for evaluation of creep rupture limit and prediction of creep rupture life are described in Section 3. Then two numerical examples are presented to validate the effectiveness and reliability of the proposed numerical methods in Section 4. Finally, some key conclusions are drawn in Section 5.

\section{Extended shakedown theory for creep rupture analysis}

Shakedown analysis allows determining permissible boundary of loading domain for thermomechanically loaded elastoplastic structures (Weichert and Ponter, 2014). If a structural element operates at the creep temperature range, the permissible boundary of loading domain is narrowed 
compared to that without consideration of the creep rupture and is dependent on the predefined service life. To determine the narrowed boundary, some additional strategies reflecting the creep rupture characteristics have to be introduced into the traditional shakedown analysis method.

Accordingly, some researchers (Barbera and Chen, 2015; Barbera et al., 2017; Chen et al., 2003; Ponter and Engelhardt, 2000) have developed an extended shakedown theory to include the creep rupture analysis, where at each material point the original yield strength is replaced by a revised yield strength but the traditional shakedown analysis formulation is not changed. The revised yield strength $\sigma_{y}^{R}\left(t_{f}, x_{l}\right)$ is determined by the smaller one of the original yield strength $\sigma_{y}\left(x_{l}\right)$ and a creep rupture strength $\sigma_{C}\left(t_{f}, \theta\left(x_{l}\right)\right)$ which is dependent on the predefined creep rupture time $t_{f}$ and the local temperature $\theta\left(x_{l}\right)$, i.e.

$$
\sigma_{y}^{R}\left(t_{f}, x_{l}\right)=\min \left\{\sigma_{y}\left(x_{l}\right), \sigma_{C}\left(t_{f}, \theta\left(x_{l}\right)\right)\right\}
$$

Although the methods used in previous works (Barbera and Chen, 2015; Chen et al., 2003; Ponter and Engelhardt, 2000) are all based upon the kinematic shakedown theorem by Koiter (Koiter, 1960), the similar extensions can still be applied to the static shakedown theorem by Melan (Melan, 1938). The material is considered isotropic, elastic-perfectly plastic (EPP) and meets the von Mises yield criterion. The extended static shakedown theorem used for creep rupture analysis can be stated as follows:

For a creeping structure, with volume $V$, subjected to thermo-mechanical loadings, the creep rupture will not occur in a given time period, $t \leq t_{f}$, if a time-independent residual stress field $\rho_{i j}\left(x_{l}\right)$ could be found so that the yield condition in (3) is satisfied at any material point $x_{l} \in V$ for arbitrary loading paths $\lambda \sigma_{i j}^{E}\left(x_{l}, t\right)$ in a prescribed loading domain.

$$
f\left(\lambda \sigma_{i j}^{E}\left(x_{l}, t\right)+\rho_{i j}\left(x_{l}\right), \sigma_{y}^{R}\left(t_{f}, x_{l}\right)\right) \leq 0
$$

where $\lambda$ is a load multiplier, $\sigma_{i j}^{E}\left(x_{l}, t\right)$ is the fictitious elastic stress of the structure, and $\sigma_{y}^{R}\left(t_{f}, x_{l}\right)$ is that defined in Eq.(2).

Using this strategy, the maximum permissible load of a structure within the specified creep rupture life, namely the creep rupture limit, can be determined directly based on the creep rupture data without knowing the detailed creep constitutive description. It is worth noting that the creep rupture assessment applies to both the monotonic and cyclic loading conditions. Based on the extended shakedown theory 
including creep rupture analysis, a numerical scheme for evaluation of the creep rupture limit will be presented in Section 3.1.

In actual situation, not only the maximum permissible load of a structure within the prescribed service life but also the creep rupture life of the structure under the prescribed loading condition is concerned by engineers. In order to distinguish between the two concerns, the former is defined as Problem 1 and the latter is defined as Problem 2 in this paper. For Problem 2, the key is to find the largest creep rupture time over which the applied loading domain always remains within the shakedown boundary. This requirement generates an inversion of the extended shakedown problem. Based on the extended shakedown theory including creep rupture analysis, a numerical scheme for optimisation of the creep rupture time will be presented in Section 3.2.

\section{Numerical procedure for creep rupture assessment}

\subsection{Numerical scheme for evaluation of creep rupture limit}

The numerical scheme (Scheme 1) for evaluation of creep rupture limit (Problem 1) is based on the extended shakedown theory including creep presented in Section 2. By replacing the original yield strength with a revised yield strength, the numerical scheme is embedded into the recently proposed SCM framework for shakedown analysis (Peng et al., 2019a, b). The description is detailed as follows.

The structures considered in this study are made of isotropic, EPP, von Mises metallic materials. For simplification, the loading history is described by the linear elastic stress fields obtained from the solved continuum solutions of elastic structure under different mechanical and thermal loads. Associated with a load multiplier $\lambda$, the loading histories are denoted as

$$
\lambda \sigma_{i j}^{E}\left(x_{l}, t\right)=\lambda \sigma_{i j}^{M}\left(x_{l}, t\right)+\lambda \sigma_{i j}^{T}\left(x_{l}, t\right)
$$

where $\sigma_{i j}^{M}\left(x_{l}, t\right)$ and $\sigma_{i j}^{T}\left(x_{l}, t\right)$ are the elastic stress fields corresponding to the applied mechanical and thermal loads, respectively. According to the theorem proposed by König (König, 1987), if a structure shakes down at all vertices of a loading domain, the structure shakes down within the loading domain. Thus, the shakedown conditions only need to be tested at these vertices of the loading history, $\sigma_{i j}^{E}\left(x_{l}, t_{k}\right), k=1,2, \cdots, r$.

The method relies on the static shakedown theorem (Melan, 1938), which aims to find the optimal 
constant residual stress field $\rho_{i j}\left(x_{l}\right)$ to obtain the maximum load multiplier $\lambda$ under Condition (3). The numerical scheme (Scheme 1) for handling Problem 1 contains two iterative loops. The inner loop performs a series of iterative computations of FE equilibrium equations to construct the timeindependent residual stress field whilst the outer loop updates the load multipliers $\lambda$ to approach to the shakedown limit one (Peng et al., 2019a, b).

For the $n$-th inner loop iteration,

1) Calculate the total stress fields $\sigma_{i j}^{(n)}\left(x_{l}, t_{k}\right)$ at these $r$ load vertices

$$
\sigma_{i j}^{(n)}\left(x_{l}, t_{k}\right)=\lambda^{(m)} \sigma_{i j}^{E}\left(x_{l}, t_{k}\right)+\rho_{i j}^{(n)}\left(x_{l}\right), \quad k=1,2, \cdots, r
$$

2) Calculate the compensation stresses $\sigma_{i j}^{C(n)}\left(x_{l}, t_{k}\right)$ at all material points at these $r$ load vertices

$$
\begin{aligned}
& \sigma_{i j}^{C(n)}\left(x_{l}, t_{k}\right)=\xi^{(n)}\left(x_{l}, t_{k}\right) \cdot \sigma_{i j}^{(n)}\left(x_{l}, t_{k}\right) \\
& \text { where } \xi^{(n)}\left(x_{l}, t_{k}\right)=\left\{\begin{array}{cc}
\frac{\bar{\sigma}^{(n)}\left(x_{l}, t_{k}\right)-\sigma_{y}^{R(n)}\left(t_{f}, x_{l}\right)}{\bar{\sigma}^{(n)}\left(x_{l}, t_{k}\right)} & \bar{\sigma}^{(n)}\left(x_{l}, t_{k}\right)>\sigma_{y}^{R(n)}\left(t_{f}, x_{l}\right) \\
0 & \bar{\sigma}^{(n)}\left(x_{l}, t_{k}\right) \leq \sigma_{y}^{R(n)}\left(t_{f}, x_{l}\right)
\end{array}\right.
\end{aligned}
$$

where $\sigma_{y}^{R(n)}\left(t_{f}, x_{l}\right)$ is determined via Eq.(2), and $\bar{\sigma}^{(n)}\left(x_{l}, t_{k}\right)$ is the von Mises equivalent value of $\sigma_{i j}^{(n)}\left(x_{l}, t_{k}\right)$. To simplify the notation, in the following text, $\sigma_{i j}^{C(n)}\left(x_{l}, t_{k}\right)$ is written as $\sigma_{i j}^{C(n)}\left(t_{k}\right)$ or $\sigma_{p q}^{C(n)}\left(t_{k}\right), \rho_{i j}^{(n)}\left(x_{l}\right)$ is written as $\rho_{i j}^{(n)}, \sigma_{i j}^{E}\left(x_{l}, t_{k}\right)$ is written as $\sigma_{i j}^{E}\left(t_{k}\right)$, and so on.

3) Solve the FE equilibrium equations and optimise the residual stress $\rho_{p q}^{(n+1)}$ for next iteration through Eqs.(7)-(9).

$$
\begin{gathered}
K_{s t} \Delta u_{t}^{(n+1)}=\sum_{k=1}^{r}\left\{\lambda^{(m)} \int_{V} B_{s p q}\left[\Delta \sigma_{p q}^{E}\left(t_{k}\right)+D_{p q i j} \Delta \varepsilon_{i j}^{\theta}\left(t_{k}\right)\right] d V\right\}+\int_{V} B_{s p q} \sigma_{p q}^{C(n)}\left(t_{k}\right) d V \\
\Delta \rho_{p q}^{(n+1)}=D_{p q i j} B_{i j t} \Delta u_{t}^{(n+1)}-\lambda^{(m)} \sum_{k=1}^{r}\left[\Delta \sigma_{p q}^{E}\left(t_{k}\right)+D_{p q i j} \Delta \varepsilon_{i j}^{\theta}\left(t_{k}\right)\right]-\sum_{k=1}^{r} \sigma_{p q}^{C(n)}\left(t_{k}\right) \\
\rho_{p q}^{(n+1)}=\rho_{p q}^{(n)}+\frac{1}{r} \Delta \rho_{p q}^{(n+1)}
\end{gathered}
$$

4) Check the convergence of $\sigma_{p q}^{C(n)}\left(t_{k}\right)$ through the criterion below 


$$
\left|\xi^{(n+1)}\left(x_{l}, t_{k}\right)-\xi^{(n)}\left(x_{l}, t_{k}\right)\right|<\delta_{1}
$$

where $\delta_{1}$ is a prescribed margin of error. If this criterion is not satisfied, return to Step 1) of the inner loop, and then the next iteration of inner loop goes on. Otherwise, the inner loop is completed.

Scheme 1: For the $m$-th outer loop iteration,

1) Complete the calculation of the inner loop.

2) Screen out the maximum value of $\xi^{(n+1)}\left(x_{l}, t_{k}\right)$ and mark it as $\xi_{\max }^{(n+1)}$, i.e.

$$
\xi_{\max }^{(n+1)}=\max \left\{\xi^{(n+1)}\left(x_{l}, t_{k}\right) \mid x_{l} \in V, k=1,2, \cdots, r\right\}
$$

3) Check the following condition

$$
\frac{\xi_{\max }^{(n+1)}}{\xi_{\max }^{(n)}} \leq \delta_{2} \text {, and } \omega>0.1
$$

where $\delta_{2}$ and $\omega$ are two parameters to control the convergence speed of creep rupture load multipliers. If Condition (12) is satisfied, $\lambda^{(m+1)}$ is determined by

$$
\lambda^{(m+1)}=\lambda^{(m)} \frac{1-\left(\omega \cdot \xi_{\max }^{(n+1)}\right) / 2}{1-\omega \cdot \xi_{\max }^{(n+1)}}
$$

and then $\omega=\omega / 2$. Otherwise, $\lambda^{(m+1)}$ is determined by

$$
\lambda^{(m+1)}=\lambda^{(m)}\left(1-\omega \cdot \xi_{\max }^{(n+1)}\right)
$$

4) Check whether the yield conditions are satisfied at all material points by the following judgment

$$
\xi_{\max }^{(n+1)}<\delta_{3}
$$

where $\delta_{3}$ is a margin of error close to zero. If Condition (15) is not satisfied, return to Step 1) of the outer loop, and then the next iteration of outer loop goes on. Otherwise, the outer loop is completed, and finally, the creep rupture limit multiplier $\lambda_{\text {creep }}$ is calculated as

$$
\lambda_{\text {creep }}=\lambda^{\text {limit }}
$$

The numerical scheme described above will lead to a series of decreasing load multipliers gradually approaching to the limit one. The finial convergent load multiplier is the creep rupture limit multiplier. This numerical scheme considers the balance between accuracy and efficiency of the method by providing some user-defined control parameters. A great advantage of this approach is its ability to be 
incorporated in standard commercial FE codes, which makes it simple, easy and user-friendly. In this paper, this has been done in Abaqus (Abaqus, 2014) using the subroutines UMAT and URDFIL. In essence, Abaqus performs the conventional incremental analysis, but through the implementation of these user subroutines Abaqus is fooled to carry out an iteration of the inner loop of the method at each increment. Note that $\sigma_{C}\left(t_{f}, \theta\left(x_{l}\right)\right)$ is relevant to the predefined creep rupture time $t_{f}$ and the local temperature $\theta\left(x_{l}\right)$. With each update of the load multiplier, the local temperature $\theta\left(x_{l}\right)$ and the creep rupture strength $\sigma_{C}\left(t_{f}, \theta\left(x_{l}\right)\right)$ at each material point change, so that the revised yield strength $\sigma_{y}^{R}\left(t_{f}, x_{l}\right)$ defined by Eq.(2) will have to be updated in each outer loop iteration.

\subsection{Numerical scheme for prediction of creep rupture life}

For a creeping structure with a specified loading history, one significant point is to answer how long the structure can service (Problem 2). Based on the extended shakedown theory including creep presented in Section 2, a numerical scheme (Scheme 2) for prediction of creep rupture life is proposed in this section.

For an ordinary metallic material, its creep rupture strength $\sigma_{C}\left(t_{f}, \theta\left(x_{l}\right)\right)$ can be represented as

$$
\sigma_{C}\left(t_{f}, \theta\left(x_{i}\right)\right)=\sigma_{C}\left(R\left(t_{f} / t_{0}\right), g\left(\theta\left(x_{i}\right) / \theta_{0}\right)\right)
$$

where $t_{0}$ and $\theta_{0}$ are two material constants, $R\left(t_{f} / t_{0}\right)$ is the creep rupture time parameter related to the creep rupture time $t_{f}$, and $g\left(\theta\left(x_{i}\right) / \theta_{0}\right)$ is the function of the temperature $\theta\left(x_{i}\right)$ of a local material point $x_{i}$. The functions $g$ and $R$ can be defined by users through material data analysis. As is known to all the creep rupture strength of a material decreases with the increase of creep rupture time and temperature. Without loss of generality, $\sigma_{C}\left(t_{f}, \theta\left(x_{l}\right)\right)$ is assumed to be in positive correlation with the values of $g$ and $R$, but $R$ and $g$ are in negative correlation with $t_{f}$ and $\theta$, respectively.

The numerical scheme (Scheme 2) for handling Problem 2 also contains two iterative loops. The inner loop is the same as that in Scheme 1 whilst the outer loop optimises the creep rupture time parameter $R$ and determines the corresponding creep rupture life $t_{f}$.

Scheme 2: For the $m$-th outer loop iteration, 
1) Complete the calculation of the inner loop.

2) Screen out the maximum value of $\xi^{(n+1)}\left(x_{l}, t_{k}\right)$ and mark it as $\xi_{\max }^{(n+1)}$, i.e.

$$
\xi_{\max }^{(n+1)}=\max \left\{\xi^{(n+1)}\left(x_{l}, t_{k}\right) \mid x_{l} \in V, k=1,2, \cdots, r\right\}
$$

3) Check the following condition

$$
\frac{\xi_{\max }^{(n+1)}}{\xi_{\max }^{(n)}} \leq \delta_{4}, \text { and } \omega>0.1
$$

where $\delta_{4}$ and $\omega$ are two parameters to control the convergence speed of $R$. If Condition (19) is satisfied, $R^{(m+1)}$ is determined by

$$
R^{(m+1)}=R^{(m)} \frac{1+\left(\omega \cdot \xi_{\max }^{(n+1)}\right) / 2}{1+\omega \cdot \xi_{\max }^{(n+1)}}
$$

and then $\omega=\omega / 2$. Otherwise, $R^{(m+1)}$ is determined by

$$
R^{(m+1)}=R^{(m)}\left(1+\omega \cdot \xi_{\max }^{(n+1)}\right)
$$

4) Check whether the yield conditions are satisfied at all material points by the following judgment

$$
\xi_{\max }^{(n+1)}<\delta_{5}
$$

where $\delta_{5}$ is a margin of error close to zero. If Condition (22) is not satisfied, return to Step 1) of the outer loop, and then the next iteration of outer loop goes on. Otherwise, the outer loop is completed, and finally, the maximum value of $R$ is calculated as

$$
R_{\text {limit }}=R^{(m+1)}
$$

5) Determine the creep rupture life $t_{f}$ via solving the equation of $R\left(t_{f} / t_{0}\right)=R_{\text {limit }}$.

\subsection{Interpretation of the two numerical schemes}

Some interpretation of the above two numerical schemes from the geometrical point of view (Weichert, 2011) is given in Fig. 1 to make it easier for the readers to understand the two problems. The first scheme (Scheme 1) can be interpreted to find the maximum load multiplier for which the loading domain is contained in the yield surface. Its geometric illustration can be described as follows: the polyhedral elastic domain with $r$ vertices, $\sigma_{i j}^{E}\left(x_{l}, t_{k}\right), k=1,2, \cdots, r$, at every point $x_{l}$ is put in a 
fixed geometric space determined by the yield surface $f\left(\lambda \sigma_{i j}^{E}\left(x_{l}, t\right)+\rho_{i j}\left(x_{l}\right), \sigma_{y}^{R}\left(t_{f}, x_{l}\right)\right)=0$, through moving and resizing the polyhedral elastic domain (see Fig. 1). It is noted that the load multiplier $\lambda$ represents the resizing of the polyhedral elastic domain, and the residual stress $\rho_{i j}\left(x_{l}\right)$ represents the moving of the polyhedral elastic domain. The maximum allowable value of load multiplier $\lambda_{\text {limit }}$ is the creep rupture limit multiplier that we need to calculate.

The second scheme (Scheme 2) can be interpreted to find the minimum yield surface required so that the yield surface can contain the loading domain. Its geometric illustration can be described as follows: the polyhedral elastic domain with $r$ vertices, $\sigma_{i j}^{E}\left(x_{l}, t_{k}\right), k=1,2, \cdots, r$, at every point $x_{l}$ is put into a geometric space determined by the yield surface $f\left(\sigma_{i j}^{E}\left(x_{l}, t\right)+\rho_{i j}\left(x_{l}\right), \sigma_{y}^{R}(R)\right)=0$, through moving the polyhedral elastic domain and resizing the yield surface (see Fig. 2). It is worth noting that the residual stress $\rho_{i j}\left(x_{l}\right)$ represents the moving of the polyhedral elastic domain, and the change of the value of creep rupture time parameter $R$ represents the resizing of the yield surface. The minimum yield surface required corresponds to a creep rupture time parameter $R_{\text {limit }}$ that we need to calculate. Finally, the creep rupture life $t_{f}$ is easily determined by solving the equation of $R\left(t_{f} / t_{0}\right)=R_{\text {limit }}$.

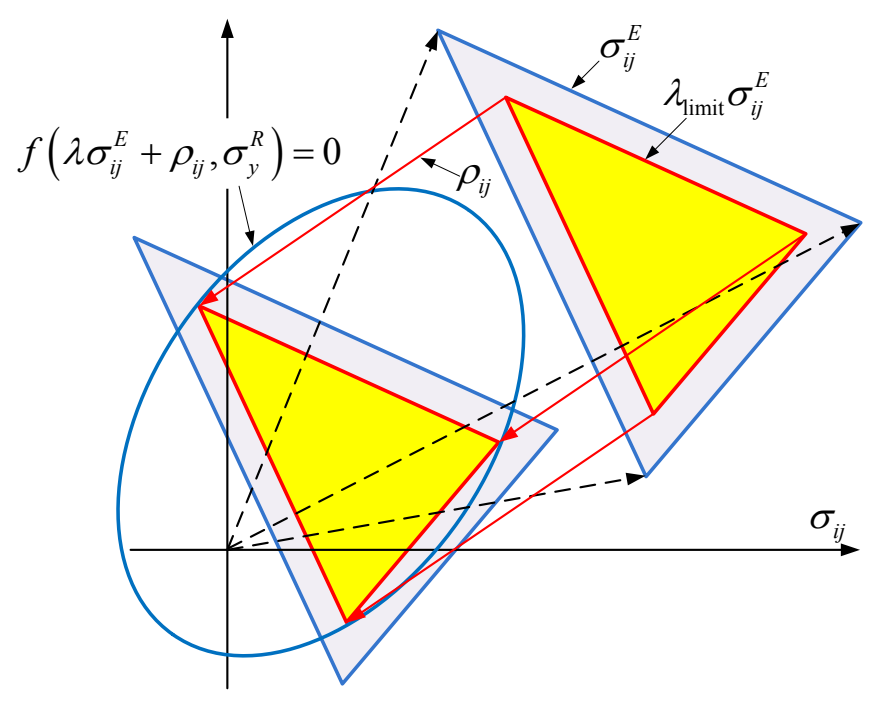

Fig. 1. Geometric illustration of Scheme 1 for evaluation of creep rupture limit. 


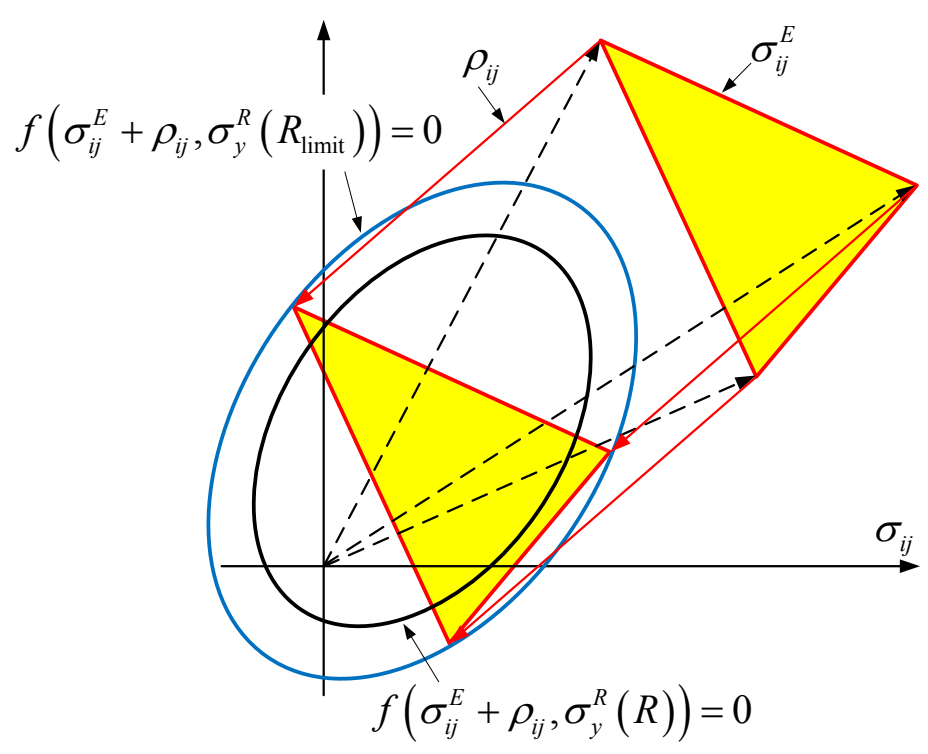

Fig. 2. Geometric illustration of Scheme 2 for prediction of creep rupture life.

\section{Numerical examples}

\subsection{Holed plate}

A square holed plate under constant uniaxial tensile load and cyclic temperature is analysed, at first, as a benchmark example. Fig. 3 shows its geometry and FE model. The plane stress model is used in this study, with the geometric parameter of $D / L=0.2$, where $D$ and $L$ are the diameter of hole and the length of plate, respectively. Because of the symmetry condition, only a quarter of the structure is modelled. The mesh includes 432 plane stress elements, each of which has nine Gaussian integration points. To facilitate comparison to verify the new approach, the same material model adopted in literature (Barbera and Chen, 2015; Chen et al., 2003) is used here. The detailed material properties include elastic modulus $E=208 \mathrm{GPa}$, Poisson's ratio $v=0.3$, coefficient of thermal expansion $\alpha=1.25 \times 10^{-5}{ }^{\circ} \mathrm{C}^{-1}$, and yield strength $\sigma_{y}=360 \mathrm{MPa}$. 


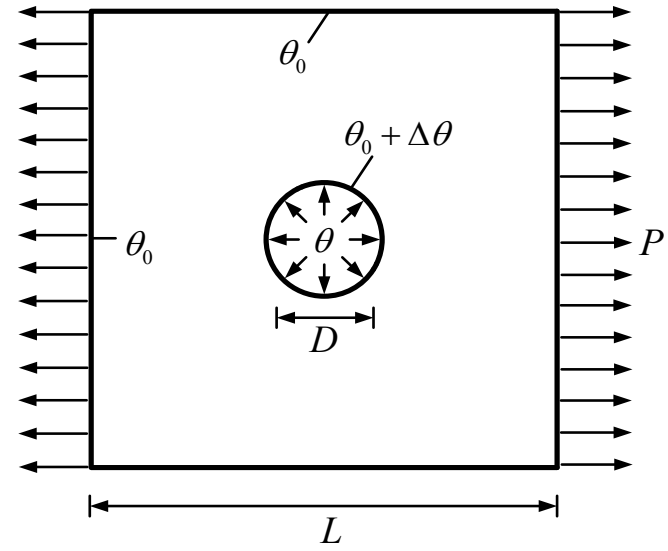

(a) Geometry

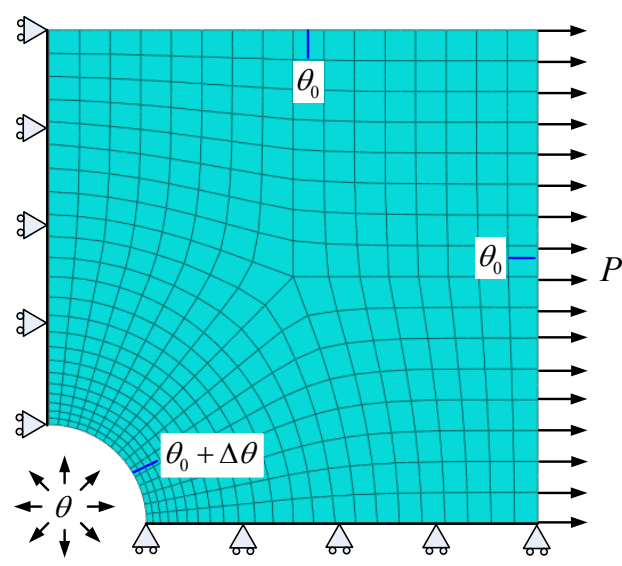

(b) FE model

Fig. 3. Holed plate under constant uniaxial tensile load and cyclic temperature.

The thermal load is determined by a non-uniform temperature field imposed over the plate, see Eq. (24), where $r$ is the distance from a point to the hole center, $\theta_{0}$ is the temperature of the midpoint of the edge of plate, and $\theta_{0}+\Delta \theta$ is the temperature of the edge of hole.

$$
\theta=\theta_{0}+\Delta \theta \cdot \ln (5 D / 2 r) / \ln (5)
$$

The reference loads chosen include the uniform tensile surface load $P=360 \mathrm{MPa}$ acting on the external surface and the thermal load determined by the non-uniform temperature field above with $\theta_{0}=200^{\circ} \mathrm{C}$ and $\Delta \theta=\Delta \theta_{0}=400^{\circ} \mathrm{C}$.

The creep rupture strength $\sigma_{C}$ of a material is dependent on the creep rupture time $t_{f}$ and the applied local temperature $\theta\left(x_{i}\right)$. To simplify the calculation, Chen et al. (2003) assumed that the creep rupture strength follows the analytical formulation of separable variables as shown below:

$$
\sigma_{C}\left(t_{f}, \theta\left(x_{i}\right)\right)=\sigma_{y} \cdot R\left(\frac{t_{f}}{t_{0}}\right) \cdot g\left(\frac{\theta\left(x_{i}\right)}{\theta_{0}}\right)
$$

where

$$
g\left(\frac{\theta\left(x_{i}\right)}{\theta_{0}}\right)=\frac{\theta_{0}}{\theta\left(x_{i}\right)-\theta_{0}}
$$

which can reflect the dependence of creep rupture strength on temperature. Let us substitute Eqs. (25) and (26) into Eq. (2), we get the relationship between the revised yield strength $\sigma_{y}^{R}$ and temperature 
$\theta$, for various creep rupture time parameters $R$, which can be drawn in Fig. 4.

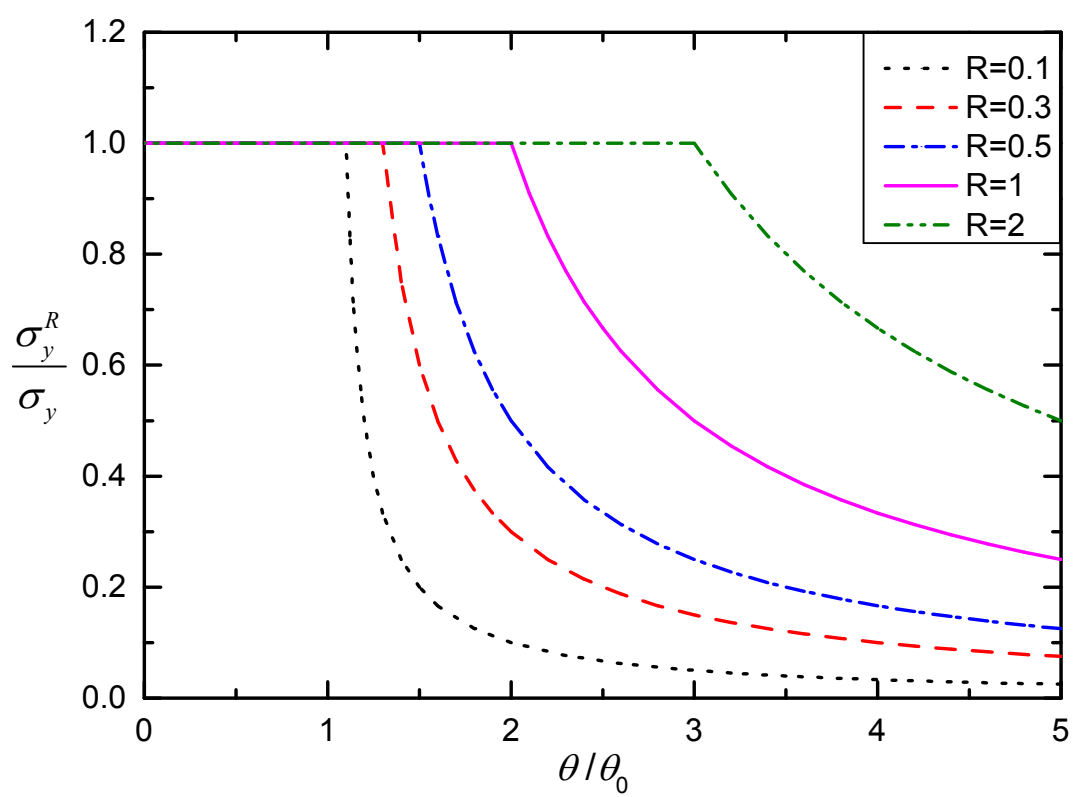

Fig. 4. Relationship between the revised yield strength and temperature for various creep rupture time parameters $R$.

The loading history considered for creep rupture assessment of the holed plate is displayed in Fig. 5, which represents a constant tensile surface load $P$ and a variable thermal load varying between zero (point $\mathrm{N}$ ) and a certain value (point $\mathrm{M}$ ). It is worth noting that, at load vertex $\mathrm{N}$, the revised yield strength $\sigma_{y}^{R}\left(t_{f}, x_{l}\right)$ is equal to the original yield strength $\sigma_{y}\left(x_{l}\right)$, while at load vertex $\mathrm{M}$, due to the high temperature, the revised yield strength $\sigma_{y}^{R}\left(t_{f}, x_{l}\right)$ of part of the body is determined by the creep rupture strength $\sigma_{C}\left(t_{f}, \theta\left(x_{l}\right)\right)$, which is lower than $\sigma_{y}\left(x_{l}\right)$.

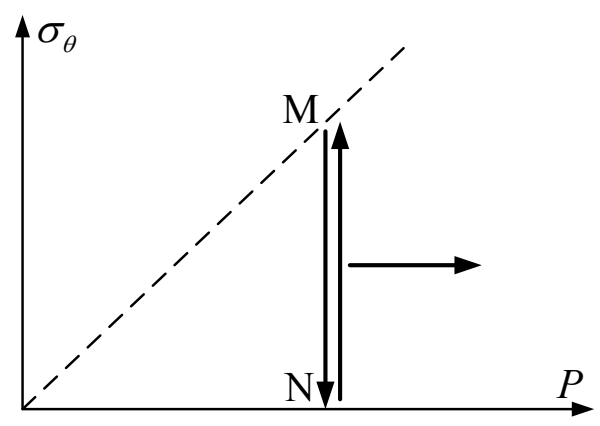

Fig. 5. Loading history considered for creep rupture assessment of the holed plate.

Numerical Scheme 1 is utilised to compute the creep rupture limits of the holed plate under various 
combiantions of constant mechanical load and cycling thermal load for seven different creep rupture time parameters, $R=0.1,0.15,0.2,0.3,0.5,1.0,2.0$. The corresponding creep rupture limit curves using the dimensionless loads $P / \sigma_{y}$ and $\Delta \theta / \Delta \theta_{0}$, are displayed in Fig. 6. For comparison purposes, the shakedown limits of the holed plate, makred as "SD" in the legend, are also presented in Fig. 6. As expected, with the decreasing of creep rupture time parameter $R$, i.e. the decreasing of revised yield strength $\sigma_{y}^{R}$ determined by Eq. (2), the creep rupture limit is reduced. It is noted that for $R=2.0$, the creep rupture limits are identical to the shakedown limits. This is because the revised yield strength $\sigma_{y}^{R}$ computed by Eqs. (2), (25) and (26) is equal to $\sigma_{y}$ throughout the body for the presribed temperature distribution given by Eq. (24), which means the failure of the plate is caused by the plastic yielding but not the creep rupture for this case. To illustrate the convergence of numerical Scheme 1, a typical convergence process of the creep rupture load multiplier $\lambda$ for the selected load point $\mathrm{A}$ shown in Fig. 6 is displayed in Fig. 7. Numerical Scheme 1 generates a series of gradually decreasing load multipliers. It is noted that in Fig. 7 the horizontal segment denotes the execution of the inner loop with no updation of load multiplier while the change of load multipliers represents the execution of the outer loop of Scheme 1.

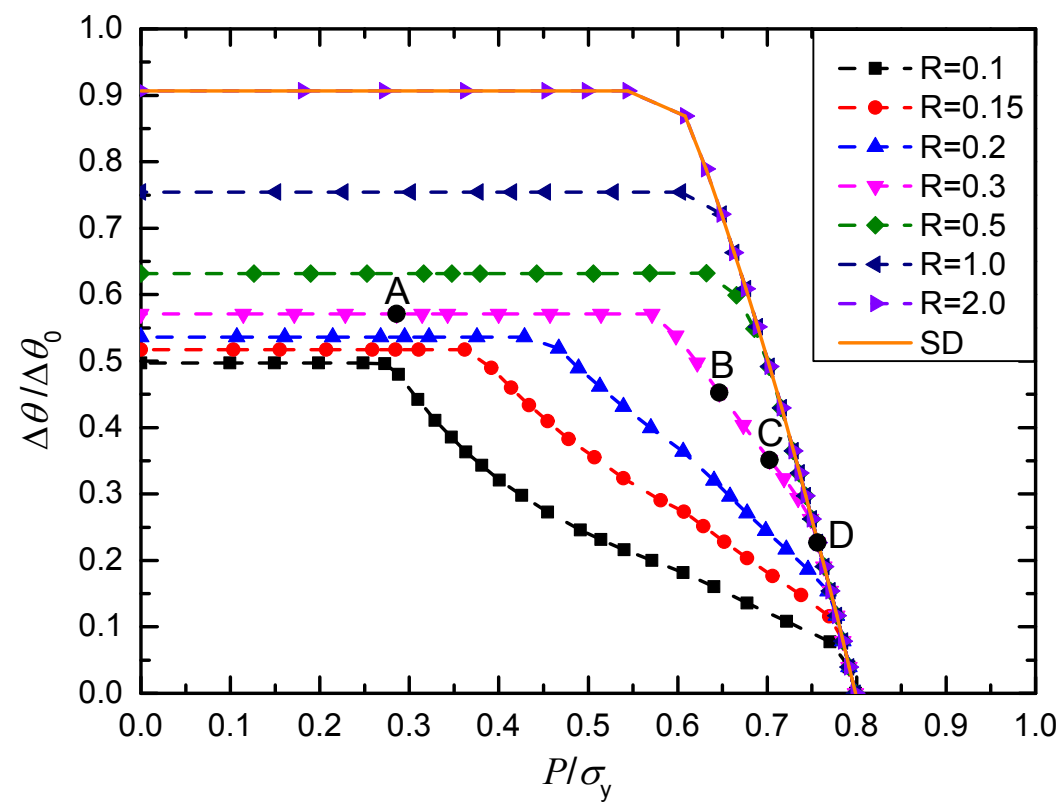

Fig. 6. Creep rupture limit curves of the holed plate under constant uniaxial tensile load and cyclic temperature for different creep rupture time parameters $R$. 


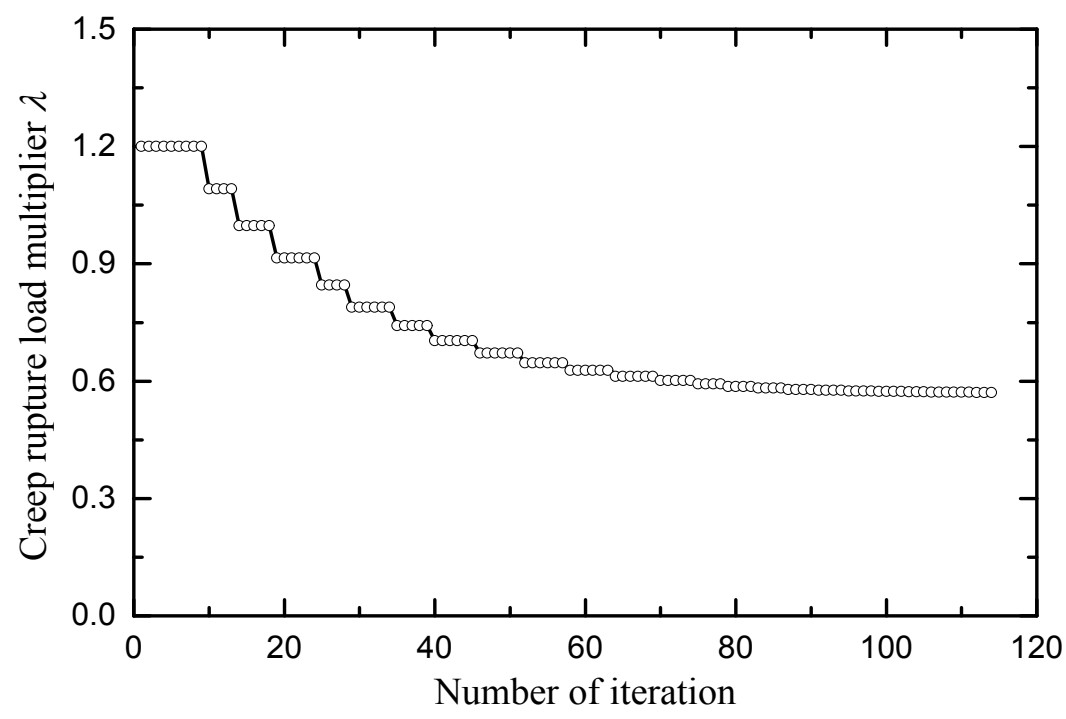

Fig. 7. Convergence process of the creep rupture load multiplier $\lambda$ for the selected load point A shown in Fig. 6.

To illustrate the effects of the temprature on the revised yield strength of the plate, the distributions of the temperature and the revised yield strength at four load points for creep rupture time parameter $R=0.3$ are presented in Fig. 8a, b, c and d, respectively, where "SDV18" represents the state varibale of temperature and "SDV19" represents the state varibale of revised yield strength. The four load points are marked as A, B, C, D in Fig. 6, whose coordinates $\left(P / \sigma_{y}, \Delta \theta / \Delta \theta_{0}\right)$ are $(0.2857,0.5713)$, $(0.6464,0.4525),(0.7027,0.3514),(0.7564,0.2269)$, respectively. At higher temperature (load point A), creep is dominant and the revised yield strength is lower than the original yield strength at a large area of the holed plate (Fig. 8a). With the decreasing of temperature (from load point A to D), the creep effect gradually diminishes and the decrease of revised yield strength due to high temperature occurs in a smaller and smaller area around the hole (from Fig. 8a to Fig. 8d).
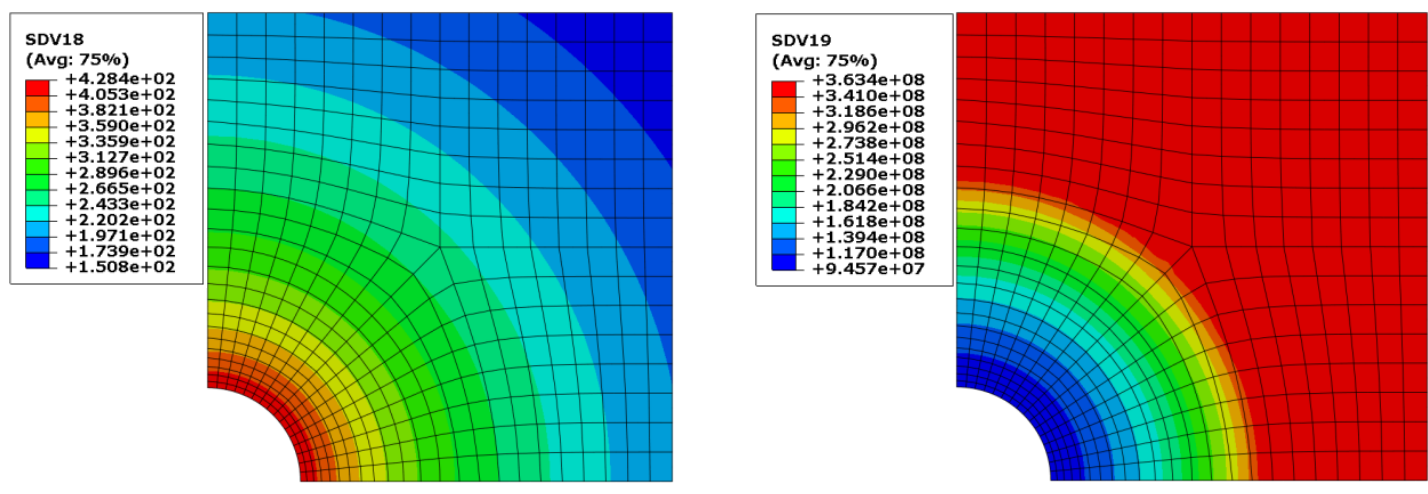

(a) At load point A with $\left(P / \sigma_{y}, \Delta \theta / \Delta \theta_{0}\right)=(0.2857,0.5713)$ 

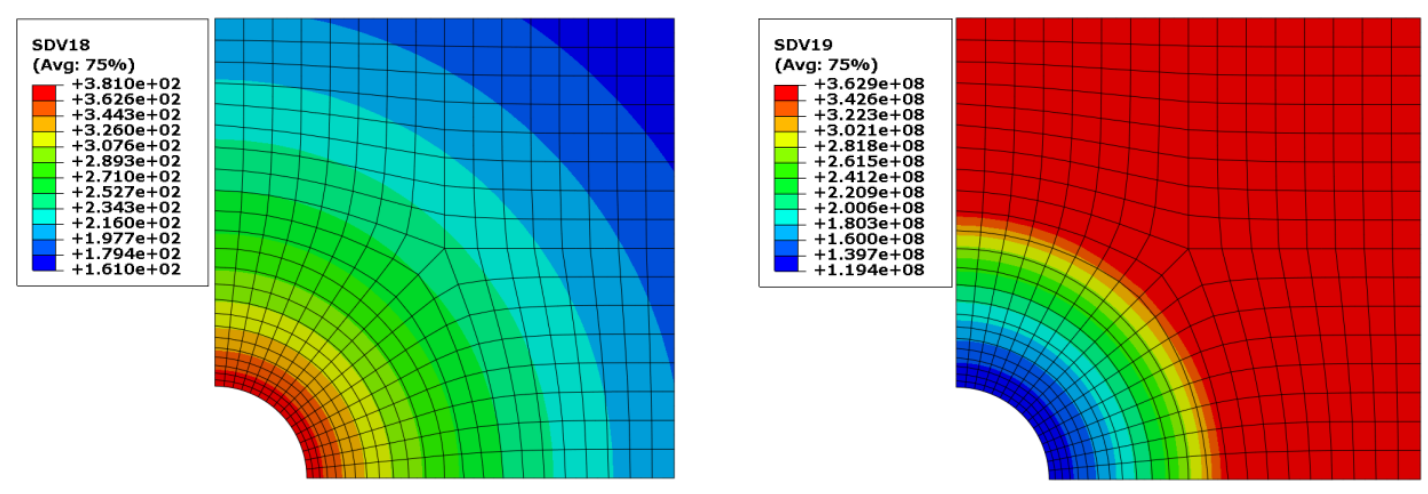

(b) At load point B with $\left(P / \sigma_{y}, \Delta \theta / \Delta \theta_{0}\right)=(0.6464,0.4525)$
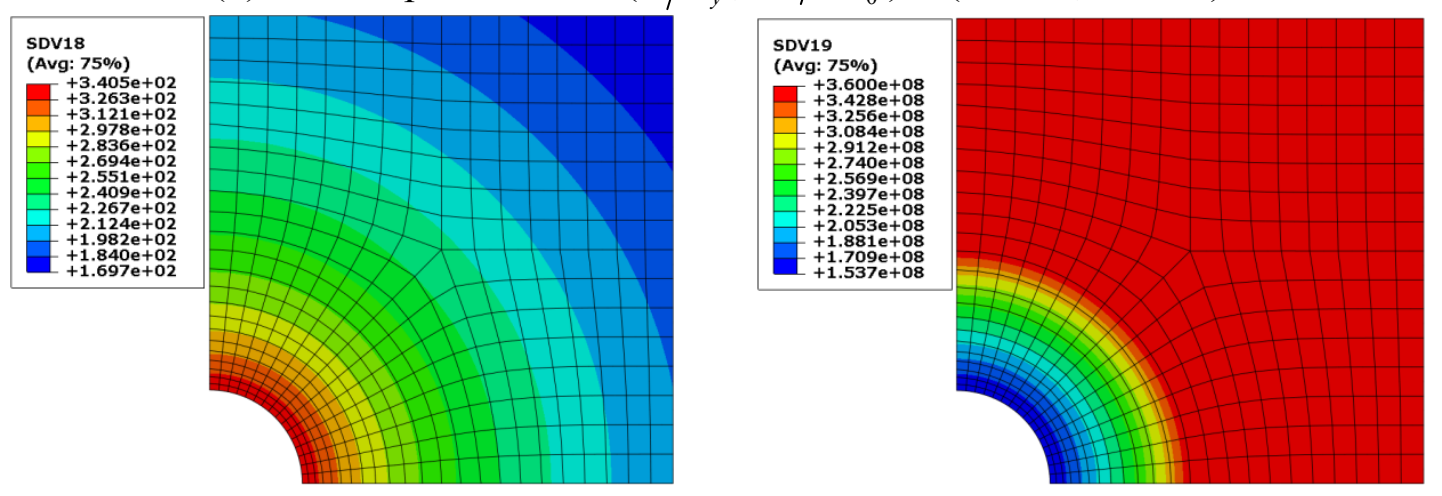

(c) At load point $\mathrm{C}$ with $\left(P / \sigma_{y}, \Delta \theta / \Delta \theta_{0}\right)=(0.7027,0.3514)$
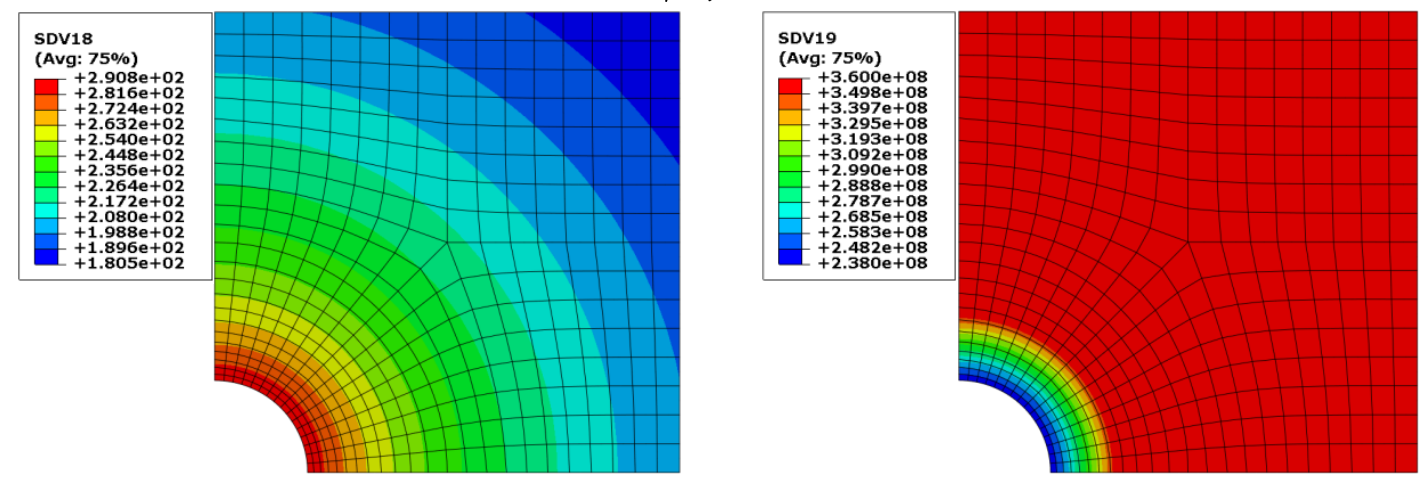

(d) At load point $\mathrm{D}$ with $\left(P / \sigma_{y}, \Delta \theta / \Delta \theta_{0}\right)=(0.7564,0.2269)$

Fig. 8. Effect of temperature marked as "SDV18" on the revised yield strength marked as "SDV19" at load points $\mathrm{A}, \mathrm{B}, \mathrm{C}$ and $\mathrm{D}$ for $R=0.3$.

To confirm these creep rupture limit curves obtained with Scheme 1 in Fig. 6, the creep rupture limits of the holed plate for $R=0.3$ are validated through some time-consuming detailed cycle-by-cycle (CBC) analyses using the revised yield strength. According to the relationship between the revised yield strength and temperature (shown in Fig. 4), the revised yield strength is not homogeneous in space distribution because of the non-uniform temperature field imposed over the holed plate. In the CBC analysis, the EPP material model is used and the material property of non-uniform yield strength 
is attached to the hold plate using the temperature-dependent data and analytical field manager options within Abaqus. The evolutions of the stresses and strains of the holed plate under the different cyclic loadings can be easily obtained through the CBC analyses. Without loss of generality, six load points $\mathrm{A}_{1}(0.2857,0.6013), \mathrm{A}_{2}(0.2857,0.5413), \mathrm{B}_{1}(0.6464,0.4725), \mathrm{B}_{2}(0.6464,0.4325), \mathrm{D}_{1}(0.7694,0.2269)$, and $\mathrm{D}_{2}(0.7434,0.2269)$ shown in Fig. 9 are selected. It is noted that load points $A_{1}, B_{1}$, and $D_{1}$ are slightly outside the creep rupture limit curve for $R=0.3$ while load points $\mathrm{A}_{2}, \mathrm{~B}_{2}$, and $\mathrm{D}_{2}$ are slightly inside the creep rupture limit curve. As a result, the histories of plastic strain magnitude of the holed plate for the six load points over the first sixty cycles are displayed in Fig. 10. It is evident that when using the revised yield strength, the responses for load points $A_{2}, B_{2}$ and $D_{2}$ show the shakedown behavior, the response for load point $\mathrm{A}_{1}$ shows the alternating plasticity behavior, and the responses for load points $B_{1}$ and $D_{1}$ show the ratcheting behavior. These changes in cyclic plastic behavior between $A_{1} / B_{1} / D_{1}$ and $A_{2} / B_{2} / D_{2}$ verify the correctness of the obtained creep rupture limit curve for $R=0.3$. For comparison purpose, the histories of plastic strain magnitude of the holed plate for the six load points using the original yield strength are also obtained with the $\mathrm{CBC}$ analysis and are shown in Fig. 10. It can be seen clearly that when using the original yield strength, the responses for all the load points show the shakedown behavior except for load point $\mathrm{D}_{1}$ whose response exhibits the ratcheting behavior. This change in cyclic plastic behavior between $\mathrm{D}_{1}$ and $\mathrm{D}_{2}$ verify the correctness of the obtained shakedown limit curve.

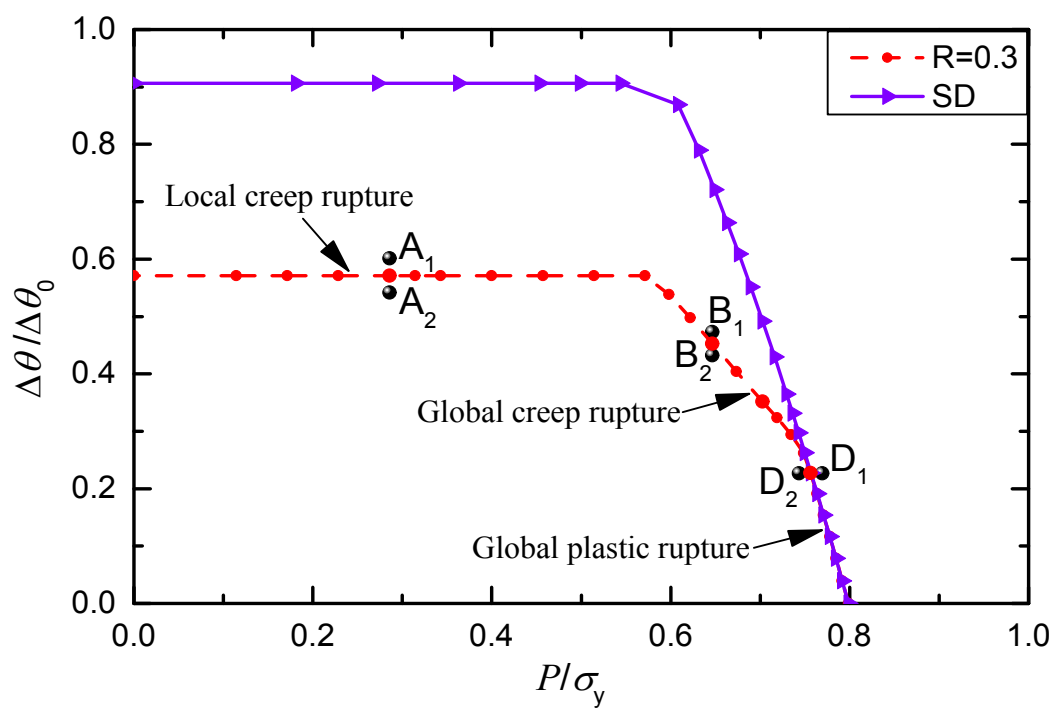

Fig. 9. Verification of the creep rupture limit curves obtained with Scheme 1 and the selected load points for CBC analysis. 

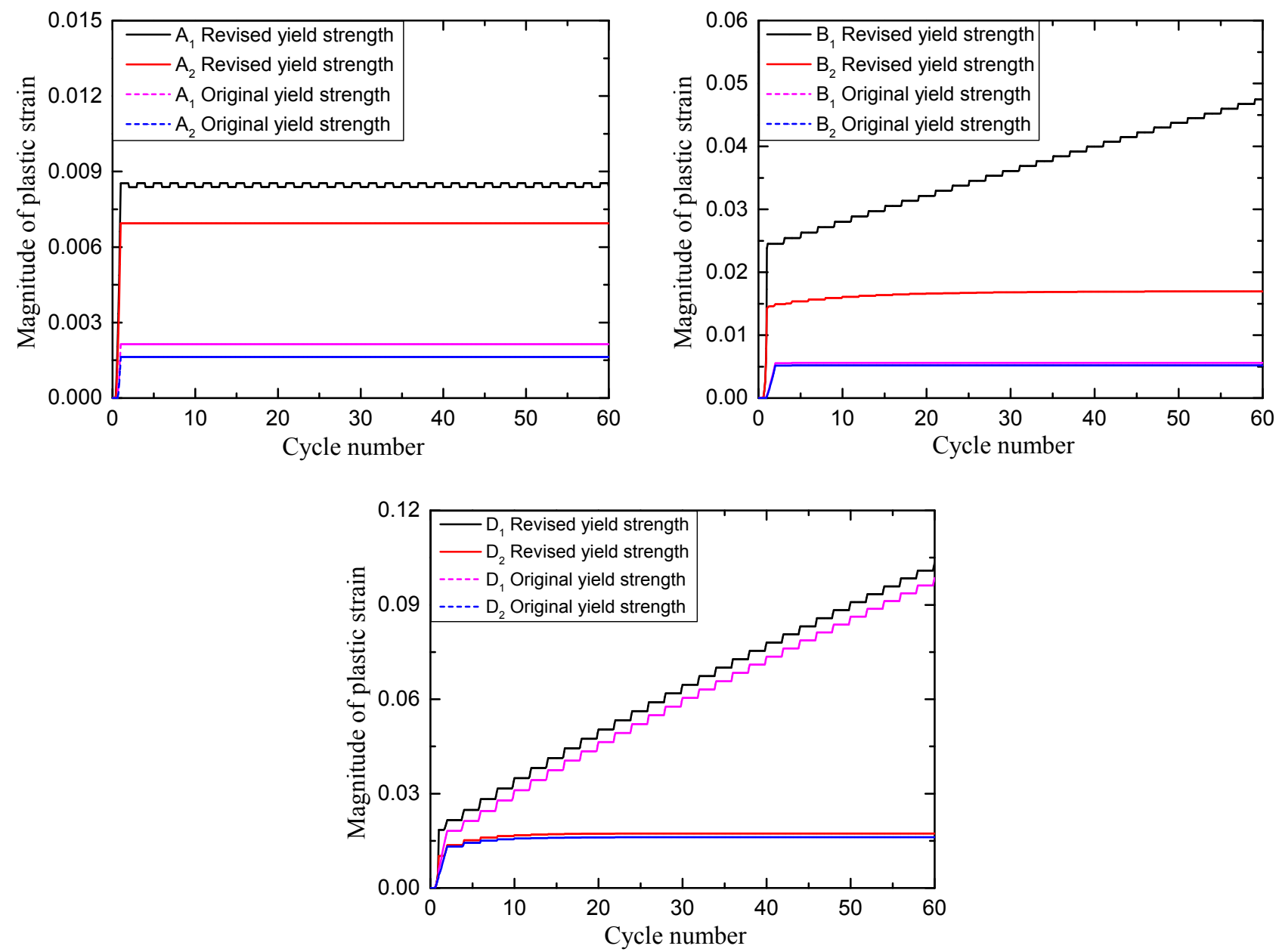

Fig. 10. Histories of plastic strain magnitude of the holed plate under different loading cases using the revised yield strength and original yield strength.

In addition, it is worth noting that three distinct segments can be observed from the creep rupture limit curve for $R=0.3$ in Fig. 9. In the first segment with load range $P / \sigma_{y} \leq 0.5713$, the failure is classified as local creep rupture because alternating plasticity behavior for load point $\mathrm{A}_{1}$ and shakedown behavior for load point $\mathrm{A}_{2}$ are detected in $\mathrm{CBC}$ analysis using the revised yield strength and shakedown behavior for load points $A_{1}$ and $A_{2}$ is detected using the original yield strength. In the second segment with load range $0.5713<P / \sigma_{y}<0.7501$, the failure is classified as global creep rupture because ratcheting behavior for load point $\mathrm{B}_{1}$ and shakedown behavior for load point $\mathrm{B}_{2}$ are detected in $\mathrm{CBC}$ analysis using the revised yield strength and shakedown behavior for load points $\mathrm{B}_{1}$ and $\mathrm{B}_{2}$ is detected using the original yield strength. In the third segment with load range $P / \sigma_{y} \geq 0.7501$, the failure is classified as global plastic rupture because ratcheting behavior for load point $\mathrm{D}_{1}$ and 
shakedown behavior for load point $\mathrm{D}_{2}$ are detected in $\mathrm{CBC}$ analysis using both the original and the revised yield strengths.

To verify the applicability of numerical Scheme 2 for prediction of creep rupture life, two load points $\mathrm{A}$ and $\mathrm{B}$ for $R=0.3$ shown in Fig. 6 are selected to calculate the respective creep ruptrue parameter. Fig. 11 displays the convergence processes of the creep rupture time parameters $R$ calculated by the proposed numerical Scheme 2 for the two selected load points. It is noted that in Fig. 11 the horizontal segment denotes the execution of the inner loop with no updation of creep rupture time parameter while the change of creep rupture time parameters represents the execution of the outer loop of Scheme 2. As expected, both of the creep rupture time parameters for load points A and B converge to 0.3 in a gradually increasing manner. Although the creep rupture life is not given directly in this example, the creep rupture life can be uniquely determined by the creep rupture time parameter if the real creep rupture data of materials are provided in actual situations. This example verifies the effectiveness of numerical Scheme 2 for prediction of creep rupture life of engineering strctures and demonstrates its potential to solve relevant problems in design and life assessment.

To demonstrate the computational efficiency of the proposed numerical approach for creep rupture assessment, a quantitative estimation of the gain in calculation time with respect to the $\mathrm{CBC}$ analysis approach is given. All the calculations are carried out on a personal computer with Intel Core i7 processor and 16 GB RAM. The running time required for calculation of the creep rupture limit of the holed plate by the proposed approach is less than $20 \mathrm{~s}$ while more than $40 \mathrm{~s}$ is required to perform a $\mathrm{CBC}$ analysis with sixty load cycles. Moreover, a CBC analysis only detects the cyclic plastic behavior of the plate under a specified load point and cannot directly determine the creep rupture limit. To evaluate the creep rupture limit, at least ten $\mathrm{CBC}$ analyses are needed to be performed with combination of the trial-and-error method. The results show that the computational efficiency of the proposed numerical approach is more than twenty times higher than that of the CBC analysis method in calculating the creep rupture limit. The proposed numerical approach is computationally efficient because it retains the framework of the original SCM (Peng et al., 2019a), in which the structural stiffness matrix keeps constant and is assembled and decomposed only once. The computation time of the proposed numerical approach for creep rupture assessment is approximately proportional to the number of iterations. 


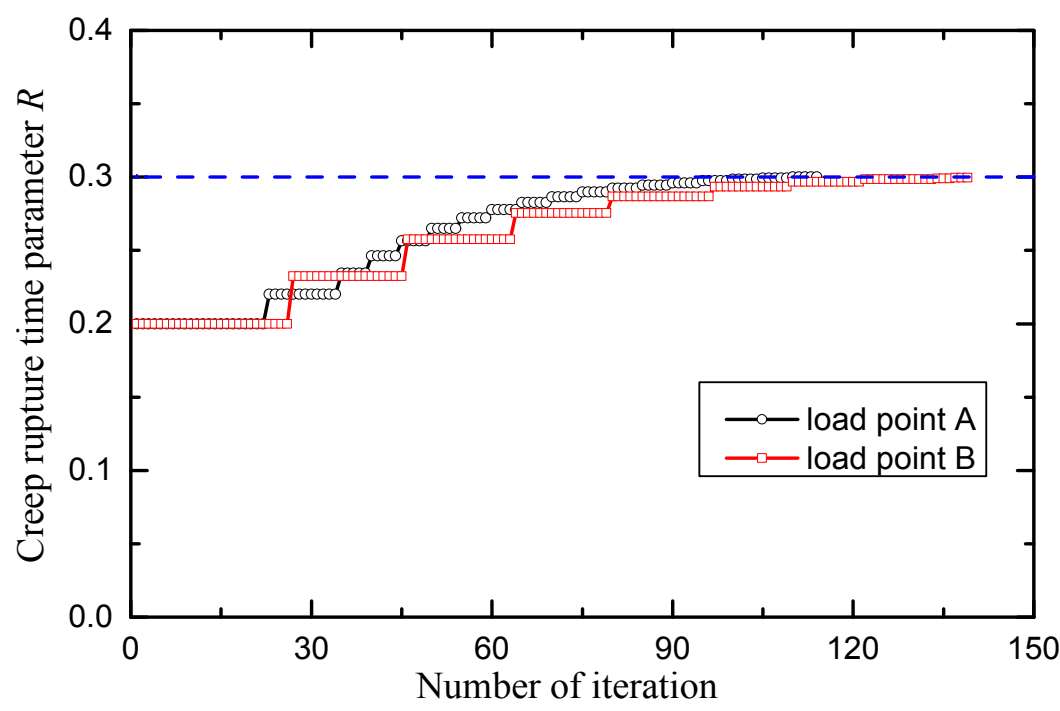

Fig. 11. Convergence processes of the creep rupture time parameters $R$ for the selected load points A and B shown in Fig. 6.

\subsection{Pipe junction}

The second numerical example is an orthogonal pipe junction operating at high temperature, as shown in Fig. 12. Because of the symmetry condition, only a quarter of FE model of the structure, including 2,272 elements and 11,641 nodes, is established for structural stress analysis using the Abaqus software (Abaqus, 2014). The main geometric parameters of the model are listed in Table 1. To simulate the work environment that temperature-changing fluid flows in the pipe junction, a constant inner pressure and a cyclic temperature load are applied to the structure. Both the initial temperature of the structure and the temperature of surrounding air $\theta_{0}$ are $20{ }^{\circ} \mathrm{C}$, and the reference temperature of hot fluid $\theta=\theta_{0}+\Delta \theta_{0}(t)$ is assumed to follow the curve with two extreme points, $20{ }^{\circ} \mathrm{C}$ and $800{ }^{\circ} \mathrm{C}$, in Fig. 12. The reference inner pressure is $P_{0}=20 \mathrm{MPa}$. The pipe junction is made of 316 stainless steel, whose main material properties are listed in Table 2 and the creep rupture strengths versus temperatures with different load duration times are given in Fig. 13 (ASME, 2013). 

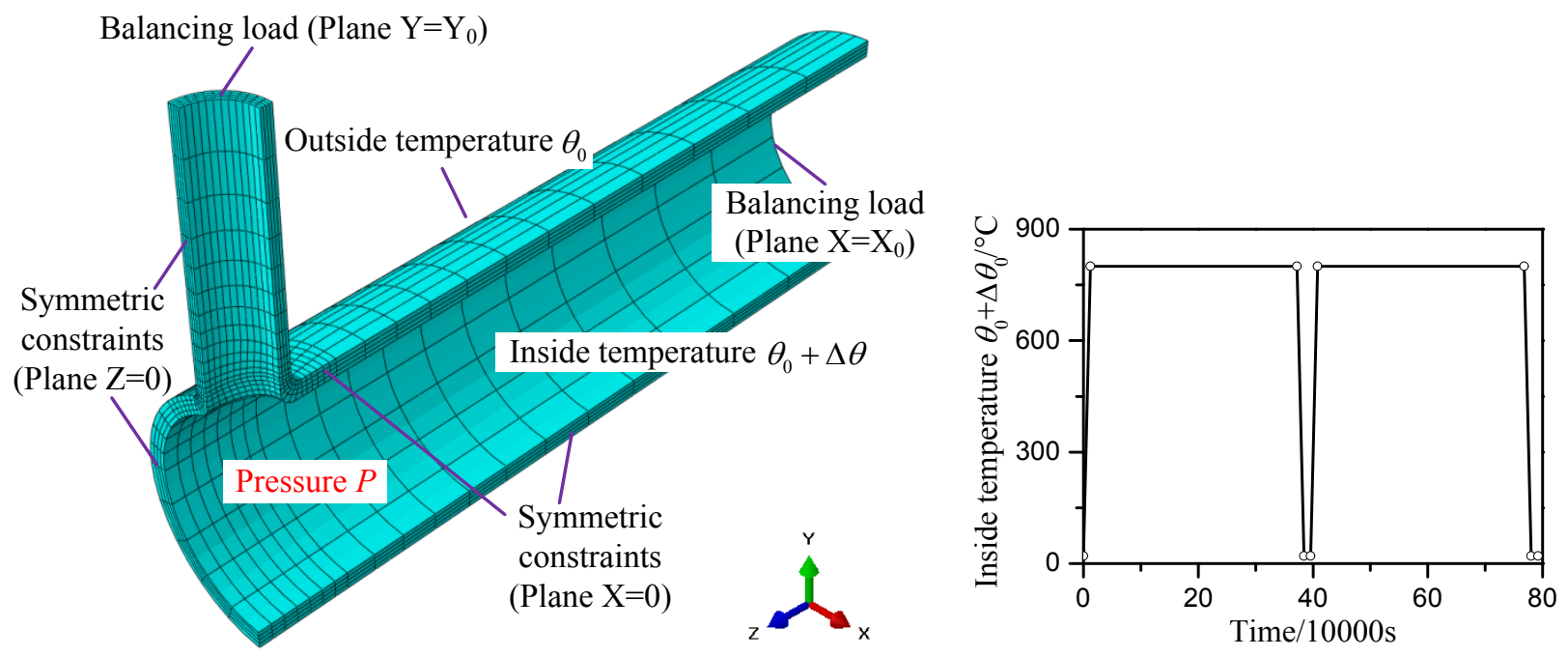

Fig. 12. FE model of the pipe junction operating at high temperature.

Table 1 Geometric parameters of the pipe junction.

\begin{tabular}{lll}
\hline Component & Parameters & Value \\
\hline Main pipe & Diameter $D_{\mathrm{m}}$ & $130 \mathrm{~mm}$ \\
& Thickness $t_{\mathrm{m}}$ & $9 \mathrm{~mm}$ \\
\multirow{2}{*}{ Nozzle } & Diameter $D_{\mathrm{n}}$ & $54 \mathrm{~mm}$ \\
& Thickness $t_{\mathrm{n}}$ & $6 \mathrm{~mm}$ \\
Rounding chamfer & Outside radius $R_{\mathrm{o}}$ & $5 \mathrm{~mm}$ \\
& Inside radius $R_{\mathrm{i}}$ & $7 \mathrm{~mm}$ \\
\hline
\end{tabular}

Table 2 Material properties of 316 stainless steel.

\begin{tabular}{ll}
\hline Parameters & Value \\
\hline Young's modulus $E$ & $1.95 \times 10^{5} \mathrm{MPa}$ \\
Poisson's ratio $v$ & 0.31 \\
Yield strength $\sigma_{y}$ & $445 \mathrm{MPa}$ \\
Density $\rho$ & $8030 \mathrm{~kg} / \mathrm{m}^{3}$ \\
Thermal conductivity $k$ & $20 \mathrm{~W} /\left(\mathrm{m}^{\circ}{ }^{\circ} \mathrm{C}\right)$ \\
Pipe-fluid transfer coefficient $h_{1}$ & $1800 \mathrm{~W} /\left(\mathrm{m}^{\left.2 \cdot{ }^{\circ} \mathrm{C}\right)}\right.$ \\
Pipe-air transfer coefficient $h_{2}$ & $1000 \mathrm{~W} /\left(\mathrm{m}^{2 \cdot}{ }^{\circ} \mathrm{C}\right)$ \\
Specific heat capacity $c$ & $502 \mathrm{~J} /\left(\mathrm{kg} \cdot{ }^{\circ} \mathrm{C}\right)$ \\
Thermal expansion coefficient $\alpha$ & $1.8 \times 10^{-5}$ \\
\hline
\end{tabular}




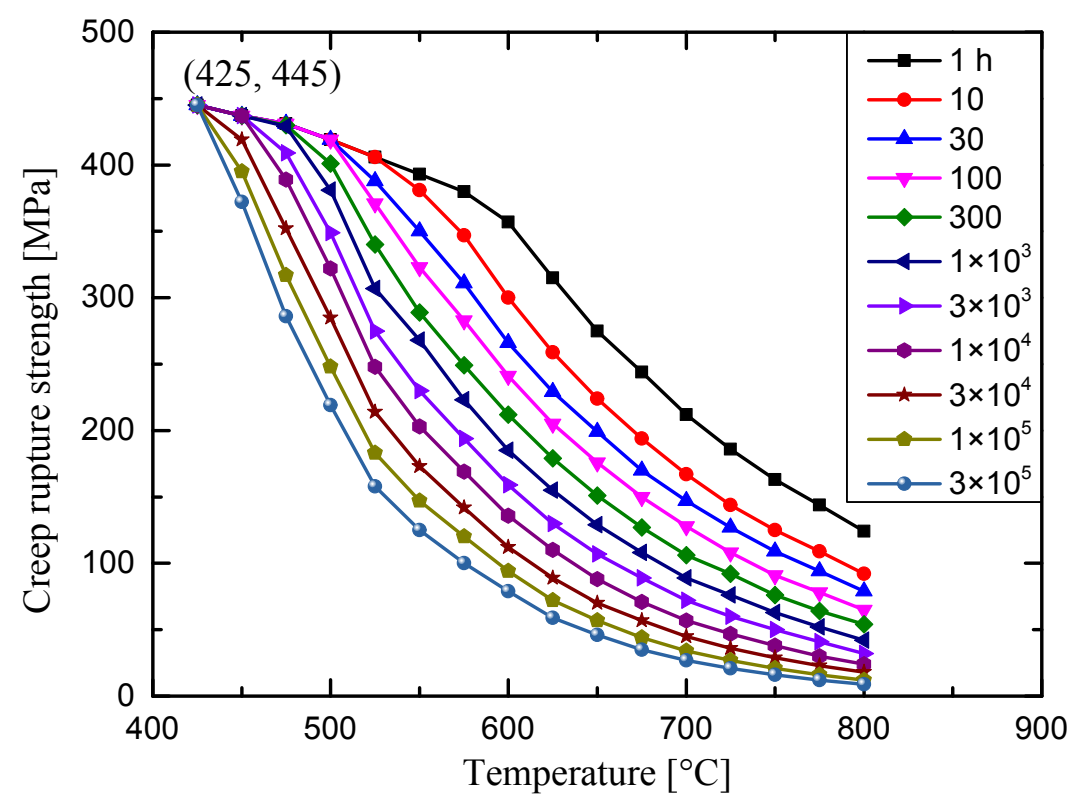

Fig. 13. Creep rupture strengths versus temperatures with different load duration times for 316 stainless steel (ASME, 2013).

As shown in Fig. 12, the boundary conditions of the FE model of the pipe junction include the symmetric constraints imposed on the cutting planes $\mathrm{Z}=0$ and $\mathrm{X}=0$ and the balancing surface loads implied to the cutting planes $\mathrm{X}=\mathrm{X}_{0}$ and $\mathrm{Y}=\mathrm{Y}_{0}$, determined by

$$
P_{F}=\frac{P D^{2}}{D^{2}-(D-2 d)^{2}}
$$

where $P_{F}$ is the evenly distributed surface loads; $P$ is the applied inner pressure; $D$ and $d$ are the diameter and thickness of cylindrical shell, respectively. Thermal transient analysis is used for computation of the temperature distribution of the pipe junction, followed by a structural static analysis for computation of its elastic stress field using the obtained temperature field. It is worth noting that the holding time at $800{ }^{\circ} \mathrm{C}$ is long enough so that the heating and cooling time can be ignored. The temperature field of the pipe junction under the reference temperature load and its corresponding thermal elastic stress field are shown in Fig. 14. The elastic stress field of the pipe junction under the reference inner pressure $P_{0}=20 \mathrm{MPa}$ is shown in Fig. 15 . 

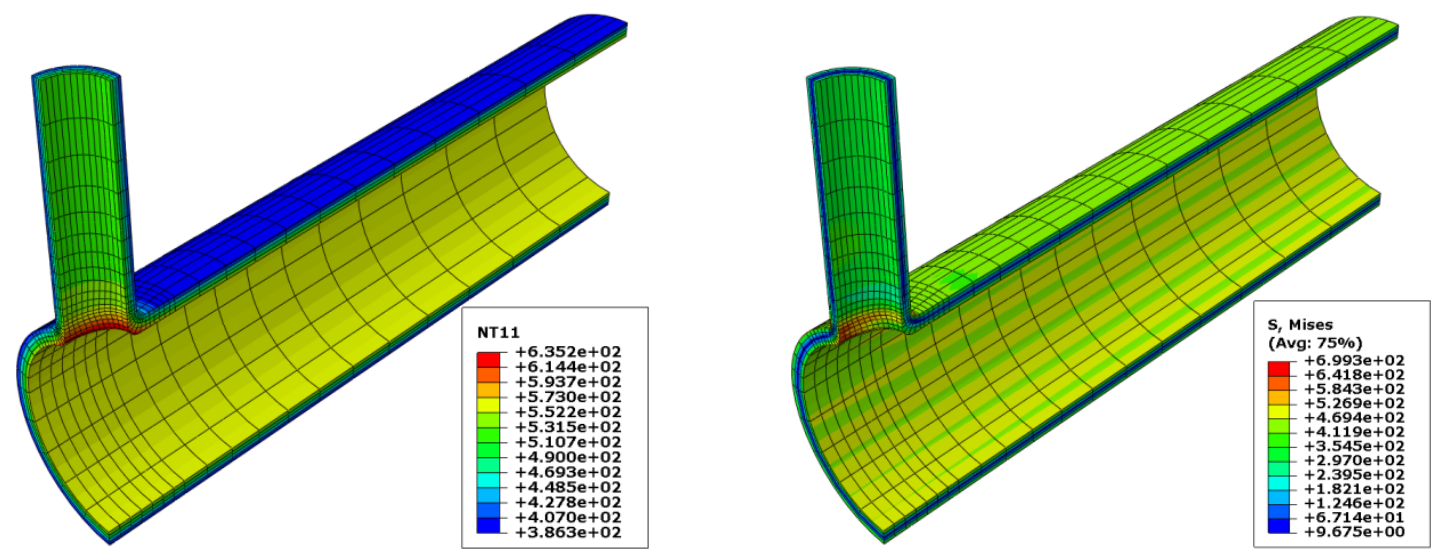

Fig. 14. Temperature distribution (left nephogram) of the pipe junction under the reference temperature load and its corresponding thermal elastic stress field (left nephogram).

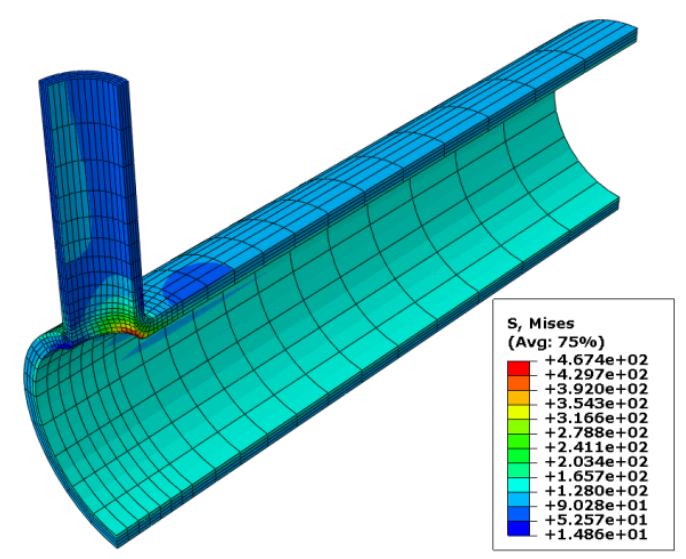

Fig. 15. Elastic stress field of the pipe junction under the reference inner pressure.

The proposed numerical Scheme 1 in this paper is utilised to calculate the creep rupture limits of the pipe junction under various combinations of the inner pressure and temperature load for different allowable creep rupture times. According to the creep rupture strength versus temperature with different load duration times displayed in Fig. 13, when the temperature is above $425{ }^{\circ} \mathrm{C}$ the revised yield strength for creep rupture analysis is replaced by the corresponding creep rupture strength, and when the temperature is below $425{ }^{\circ} \mathrm{C}$ the original yield strength of $445 \mathrm{MPa}$ is used. These creep rupture data are embedded in the numerical Scheme 1 using the linear interpolation method so that the creep rupture strength for any temperature can be automatically calculated in analysis. All numerical calculations show good convergence. As results, Fig. 16 presents four creep rupture limit curves of the pipe junction under constant inner pressure and cycling thermal load for the prescribed service life 1 $\mathrm{h}, 100 \mathrm{~h}, 10,000 \mathrm{~h}$, and 300,000 h, respectively. 
It is evident from Fig. 16 that the four creep rupture limit curves show a Bree-like shape, where the four curves are obviously different in the case of low inner pressure but coincide in the case of high inner pressure. Similar to Fig. 9, each of creep rupture limit curve is divided into three segments including global plastic rupture, global creep rupture and local creep rupture. In the local creep rupture segment, the failure of the pipe junction is due to the creep rupture of local material points. In the global creep rupture segment, the failure of the pipe junction is due to the creep rupture of large area material points. In the global plastic rupture segment, the failure of the pipe junction is due to the ratcheting mechanism of structure. As displayed in Fig. 13, with the increasing of the load duration time, the creep rupture strength at the same creep temperature is decreased. Therefore among the four creep rupture limit curves in Fig. 16, the creep rupture limits for the prescribed service life $1 \mathrm{~h}$ (with the highest creep rupture strength) are higher than these for other kinds of prescribed service life in both the local creep rupture and global creep rupture segments.

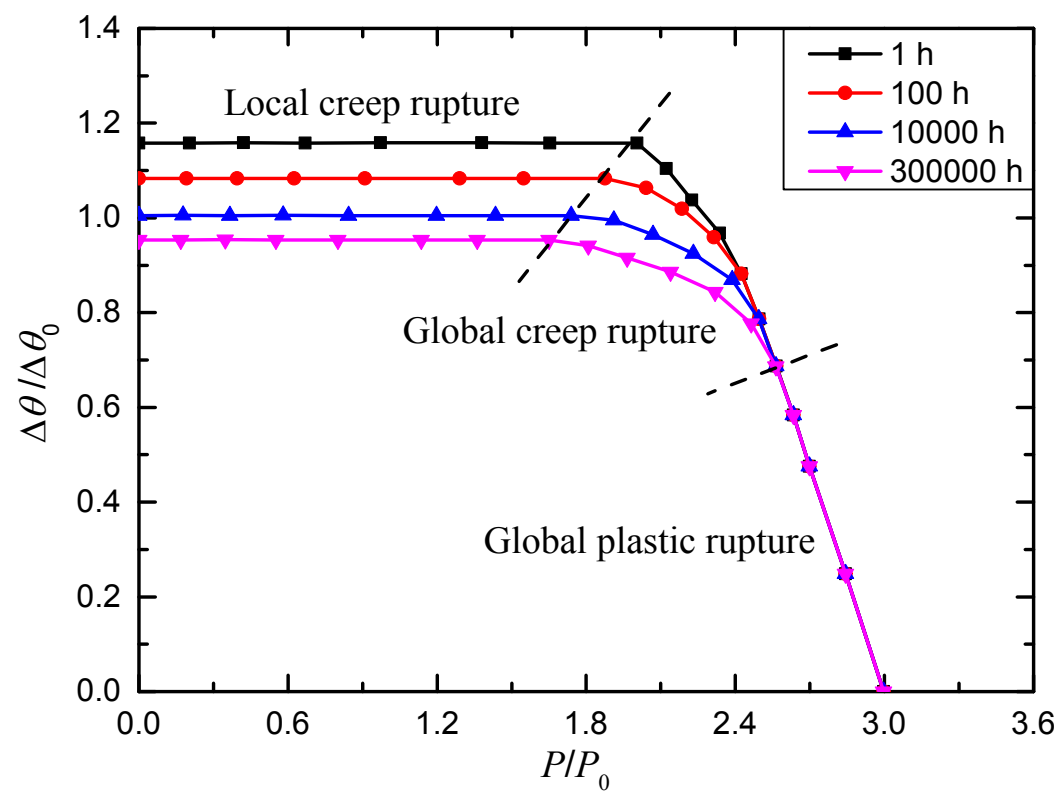

Fig. 16. Creep rupture limit curves for the pipe junction under constant inner pressure and cyclic thermal load for four kinds of prescribed service life.

\section{Conclusions}

Shakedown theories have been extended for creep rupture assessment of ductile metallic materials through replacing the original yield strength with a revised yield strength considering creep effect (Ainsworth, 2003; Chen et al., 2003). They have been further developed and successfully incorporated 
into the SCM framework in this work. Two distinct numerical schemes have been proposed to evaluate the creep rupture limit and predict the creep rupture life, respectively. To validate the reliability of two numerical schemes, two kinds of creep rupture analysis problems of a holed plate have been solved and analysed, and the detailed $\mathrm{CBC}$ analyses have been done to confirm the applicability of the proposed methods. Then a numerical example of a pipe junction with cyclic high temperature and constant inner pressure has been given to illustrate the performance and application of the proposed numerical schemes for practical engineering problems. Key conclusions are drawn as follows:

1. The proposed two numerical schemes reserve the computational advantage of the SCM, and can be easily incorporated into commercial FE codes, such as Abaqus in this work, which allows them to become the general computational tools for creep rupture assessment of complex engineering structures. Both of the two numerical schemes show good convergence, where Scheme 1 generates a series of decreasing creep rupture multipliers and Scheme 2 generates a series of increasing creep rupture time parameters.

2. For the typical example of the holed plate, the creep rupture limit curves for various creep rupture time parameters are obtained by Scheme 1 and the creep rupture time parameters for different prescribed load points are verified to converge to the target values by Scheme 2. The detailed CBC analyses detect the distinct cyclic response behaviors for the adjacent load points on both sides of the curve, which confirms the good accuracy of these calculated creep rupture limits. In addition, three failure mechanisms including global plastic rupture, global creep rupture, and local creep rupture are observed and revealed on the creep rupture limit curve. For the numerical example of the pipe junction, the creep rupture limit curves for four kinds of prescribed service life are obtained using actual creep rupture data, and three failure mechanisms are also observed.

3. The extended shakedown theory including creep has been successfully incorporated into the SCM framework, achieving the calculation of creep rupture limit and prediction of creep rupture life based on limited creep rupture data of material without knowledge of the detailed creep constitutive equations. The proposed numerical schemes have been proved to be effective and reliable for creep rupture assessment of high temperature structures and further solving practical industrial problems. 


\section{Acknowledgements}

This work is supported by the National Key Research and Development Program of China (Grant No. 2017YFF0210704, 2016YFC0801905) and the National Natural Science Foundation of China (Grant No. 11672147).

\section{References}

Abaqus, 2014. Dassault Systems, Version 6.14.

Ainsworth, R., 2003. R5: Assessment Procedure for the High Temperature Response of Structures. British Energy Generation Ltd 3.

ASME, 2013. Boiler \& Pressure Vessel Code: An international Code, Rules for Construction of Nuclear Facility Components, Division 1-Subsection NH, New York.

Barbera, D., Chen, H., 2015. Creep rupture assessment by a robust creep data interpolation using the Linear Matching Method. Eur J Mech a-Solid 54, 267-279.

Barbera, D., Chen, H., Liu, Y., Xuan, F., 2017. Recent Developments of the Linear Matching Method Framework for Structural Integrity Assessment. Journal of Pressure Vessel Technology 139, 051101-051109.

Chen, H.F., Engelhardt, M.J., Ponter, A.R.S., 2003. Linear matching method for creep rupture assessment. International Journal of Pressure Vessels and Piping 80, 213-220.

Chen, H.F., Ponter, A.R.S., 2001. Shakedown and limit analyses for 3-D structures using the linear matching method. International Journal of Pressure Vessels and Piping 78, 443-451.

Chen, H.F., Ponter, A.R.S., Ainsworth, R.A., 2006. The linear matching method applied to the high temperature life integrity of structures. Part 1. Assessments involving constant residual stress fields. International Journal of Pressure Vessels and Piping 83, 123-135.

Dyson, B., 2000. Use of CDM in Materials Modeling and Component Creep Life Prediction. Journal of Pressure Vessel Technology 122, 281-296.

Kachanov, L.M., 1958. On destruction in creeping of materials. In: Izvestia Akademii Nauk SSSR, 8. Otdelenie Tekhnicheskich Nauk.

Koiter, W.T., 1960. General theorems for elastic-plastic solids, in: Sneddon, JN, Hill, R (Eds.), Progress in Solid Mechanics. North-Holland: Amsterdam, pp. 167-221.

König, J.A., 1987. Shakedown of elastic-plastic structures. Elsevier, Warszawa, Poland.

Melan, E., 1938. Zur Plastizität des räumlichen Kontinuums. Ingenieur-Archiv 9, 116-126.

Murakami, S., 2000. Computational methods for creep fracture analysis by damage mechanics. Computer Methods in Applied Mechanics \& Engineering 183, 15-33.

Peng, H., Liu, Y., Chen, H., 2019a. A numerical formulation and algorithm for limit and shakedown analysis of large-scale elastoplastic structures. Comput Mech 63, 1-22.

Peng, H., Liu, Y., Chen, H., 2019b. Shakedown analysis of elastic-plastic structures considering the effect of temperature on yield strength: Theory, method and applications. European Journal of Mechanics - A/Solids 73, 318-330.

Peng, H., Liu, Y., Chen, H., Shen, J., 2018. Shakedown analysis of engineering structures under multiple variable mechanical and thermal loads using the stress compensation method. Int J Mech Sci 140, 361-375.

Ponter, A.R.S., Engelhardt, M., 2000. Shakedown limits for a general yield condition: implementation and application for a Von Mises yield condition. Eur J Mech a-Solid 19, 423-445.

Rabotnov, Y.N., 1969. Creep problems in structural members. North-Holland Pub. Co., Amsterdam, London. 
Weichert, D., 2011. A historical view on the development of shakedown theory. Institute of General Mechanics RWTH Aachen University, http://www.iam.rwth-aachen.de/fileadmin/media/57/Weichert_GAMM2011.pdf.

Weichert, D., Ponter, A., 2014. A historical view on shakedown theory, in: Stein, E. (Ed.), The History of Theoretical, Material and Computational Mechanics-Mathematics Meets Mechanics and Engineering. Springer, pp. 169-193. 